\title{
Nghiên cứu ảnh hưởng các dạng tồn tại của thạch cao FGD tới tính chất xi măng siêu Sulfate
}

\author{
Trịnh Thị Châm ${ }^{1}$, Lưu Thị Hồng ${ }^{1}$, Đỗ Đình Đức ${ }^{1}$, Phạm Thanh $\mathrm{Mai}^{2}$ \\ ${ }^{1}$ Viện Vật liệu xây dựng \\ ${ }^{2}$ Trường Đại học Kiến trúc Hà Nội
}

\section{TỪ KHOÁ}

Xi măng siêu ít clanhke

Xi măng siêu Sulfate

Thạch cao FGD

\begin{abstract}
TÓM TẮT
Bài báo này trình bày về khả năng sử dụng thạch cao FGD (Flue-Gas Desulfurization) làm nguyên liệu sản xuất xi măng siêu Sulfate (SSC - superSulfated cement) thỏa mãn tiêu chuẩn BS EN 15743:2010 + A1:2015, đồng thời cũng nghiên cứu các ảnh hưởng của các dạng tồn tại của thạch cao FGD tới tính chất của loại xi măng này. Kết quả nghiên cứu cho thấy thạch cao FGD được kích hoạt nhiệt (heat-activated - dạng hemihydrat và anhydrit) có tác dụng tốt với sự phát triển cường độ của đá xi măng. Đồng thời, các mẫu cũng bền trong các môi trường xâm thực Sulfate và nước biển. Kết quả thử nghiệm thành phần khoáng và vi cấu trúc của hồ xi măng cho thấy: sản phẩm thủy hóa chủ yếu là khoáng ettringite, gypsum và 1 phần khoáng C-S-H. Nhiệt thủy hóa của các mẫu thử nghiệm đều đáp ứng yêu cầu loại tỏa nhiệt thấp hoặc tỏa nhiệt rất thấp theo tiêu chuẩn TCVN 7712:2013, độ co khô của các mẫu thử nghiệm đáp ứng yêu cầu của tiêu chuẩn TCVN 9501:2013.
\end{abstract}

\begin{abstract}
This paper presents the possibility of using FGD gypsum (Flue-Gas Desulfurization) as a raw material for the production of supersulphated cement (SSC) that meets BS EN 15743:2010+A1:2015, and also studies the effects of existing forms of FGD to the properties of this cement. Research results show that heat-activated FGD has a good effect on the strength development of cement. At the same time, the samples are also resistant in sulphate and seawater environment. The test results of mineral composition and microstructure of cement paste showed that: the main hydration products are ettringite, gypsum and a part of C-S-H minerals. The heat of hydration of the test samples all met the requirements of low heat or very low heat emission according to TCVN 7712:2013, the drying shrinkage of samples met the requirements of TCVN 9501:2013.
\end{abstract}

1. Giới thiệu về xi măng siêu Sulfate (Super Sulfated cement - SSC)

Xi măng siêu Sulfate (SuperSulfated cement - SSC) là loại xi măng được chế tạo bằng sử dụng xỉ hạt lò cao nghiền mịn (GGBFS) làm thành phần chính, thạch cao làm chất hoạt hóa Sulfate và clanhke hoặc vôi làm chất hoạt hóa kiềm. Các nguyên liệu không cần phải nung, chỉ cần nghiền tới độ mịn theo yêu cầu rồi trộn cùng với nhau để chế tạo SSC. Do đó, SSC chế tạo đơn giản, tiêu thụ ít năng lượng và phát thải ít $\mathrm{CO}_{2}$ hơn so với OPC. Vì thế việc sử dụng SSC cũng được coi là loại xi măng tiết kiệm năng lượng và bảo vệ môi trường.

Thông thường, xi măng siêu Sulfate được chế tạo từ xỉ hạt lò cao, canxi Sulfate (có thể ở dạng dihydrat, hemihydrate và anhydrite), trong đó xỉ hạt lò cao chiếm $75 \%$ đến $85 \%$, canxi Sulfate chiếm $5 \%$ đến $20 \%$ và 1 $\%$ đến $5 \%$ chất hoạt hóa kiềm (có thể là clanhke xi măng, vôi dạng $\left.\mathrm{Ca}(\mathrm{OH})_{2}, \mathrm{CaO} ..\right)$.

Thạch cao FGD - Flue-Gas Desulfurization gypsum - là sản phẩm của quá trình khử SOx thải ra ở ống khói nhà máy nhiệt điện đốt than có hàm lượng lưu huỳnh lớn bằng cách sử dụng bột đá vôi (hoặc vôi) nghiền mịn ở dạng hồ lỏng để hấp phụ khí SOx. Thạch cao FGD chủ yếu chứa $\mathrm{CaSO}_{4} \cdot 2 \mathrm{H}_{2} \mathrm{O}$. Trong nghiên cứu này, thạch cao $\mathrm{FGD}$ được sử dụng ở 03 dạng với vai trò là chất hoạt hóa Sulfate trong hỗn hợp xi măng - xỉ.

\section{Nguyên vật liệu sử dụng cho nghiên cứu}

Nguyên liệu để chế tạo xi măng siêu Sulfate sử dụng trong đề tài bao gồm: clanhke của Công ty cổ phần xi măng Hoàng Long, thạch cao tự nhiên Oman, xỉ lò cao nghiền mịn của công ty Hưng Nghiệp Formosa - được cung cấp bởi công ty CHC Việt Nam, thạch cao FGD của Nhà máy nhiệt điện Nghi Sơn I. Riêng đối thạch cao FGD, đề tài sử dụng ở cả 03 dạng tồn tại gồm: nguyên khai $\left(\mathrm{CaSO}_{4} \cdot 2 \mathrm{H}_{2} \mathrm{O}\right)$, hemihydrat $\left(\mathrm{CaSO}_{4} \cdot 0.5 \mathrm{H}_{2} \mathrm{O}\right)$ và khan hoàn toàn $\left(\mathrm{CaSO}_{4}\right)$.

Thành phần hóa của các nguyên liệu thể hiện trong Bảng 1.

\subsection{Xi măng}

Xi măng được chuẩn bị bằng cách nghiền clanhke Hoàng Long cùng $4 \%$ thạch cao Oman trong máy nghiền bi thí nghiệm. Độ mịn xác 
định theo phương pháp sàng với lượng sót sàng 0,08 mm là 5,6 \%. Bề mặt riêng của xi măng, theo phương pháp Blaine là $3540 \mathrm{~cm}^{2} / \mathrm{g}$. Các tính chất cơ lý của xi măng, được thử nghiệm theo TCVN 6017:2015 [1] và TCVN 6016:2011 [2], được thể hiện trong Bảng 2 và Bảng 3.

\subsection{Xỉ lò cao nghiền mịn (GGBFS)}

Xỉ lò cao nghiền mịn Formosa được lấy từ trạm nghiền của công ty CHC Việt Nam. Các tính chất vật lý của xỉ lò cao Formosa thể hiện trong Bảng 4.

\section{Bảng 1.}

Thành phần hóa của các nguyên liệu.

\begin{tabular}{|c|c|c|c|c|c|c|c|c|c|c|}
\hline Nguyên liệu & $\mathrm{SiO}_{2}$ & $\mathrm{Al}_{2} \mathrm{O}_{3}$ & $\mathrm{Fe}_{2} \mathrm{O}_{3}$ & $\mathrm{CaO}$ & $\mathrm{MgO}$ & $\mathrm{SO}_{3}$ & $\mathrm{TiO}_{2}$ & $\mathrm{~K}_{2} \mathrm{O}$ & $\mathrm{Na}_{2} \mathrm{O}$ & MKN \\
\hline Xỉ hạt lò cao Formosa & 34,00 & 14,53 & 0,83 & 38,50 & 8,06 & 0,07 & 0,12 & 0,24 & 0,31 & $-0,25$ \\
\hline Clanhke Hoàng Long & 19,66 & 5,02 & 3,03 & 63,00 & 1,81 & 1,85 & 0,12 & 0,83 & 0,14 & 3,08 \\
\hline Thạch cao Oman & 0,14 & 0,04 & 0,03 & 30,94 & 0,20 & 43,98 & 0,02 & 0,03 & 0,02 & 21,19 \\
\hline
\end{tabular}

\section{Bảng 2.}

Tính chất cơ lý của xi măng.

\begin{tabular}{|c|c|c|c|}
\hline NTC, $\%$ & BĐĐK, min & KTĐK, min & Độ ồn định thể tích, theo phương pháp Le Chatelier, mm \\
\hline 27,15 & 105 & 150 & 0,6 \\
\hline
\end{tabular}

\section{Bảng 3.}

Cường độ nén, cường độ uốn của mẫu xi măng.

\begin{tabular}{|c|c|c|c|c|c|c|}
\hline \multirow{2}{*}{ Tên mẫu } & \multicolumn{3}{|c|}{ Cường độ uốn, MPa } & \multicolumn{3}{|c|}{ Cường độ nén, MPa } \\
\cline { 2 - 7 } & 3 ngày & 7 ngày & 28 ngày & 3 ngày & 7 ngày & 28 ngày \\
\hline OPC Hoàng Long & 5,5 & 6,3 & 9,45 & 23,03 & 33,03 & 50,64 \\
\hline
\end{tabular}

Bảng 4. Tính chất vật lý của xỉ lò cao Formosa.

\begin{tabular}{|l|c|c|c|c|}
\hline \multirow{2}{*}{ Nguyên vật liệu } & \multirow{2}{*}{ Độ ẩm (\%) } & \multicolumn{2}{|c|}{ Độ mịn (\%) } & $\begin{array}{c}\text { Tỷ diện, theo pp Blaine, } \\
\mathrm{cm}^{2} / \mathrm{g}\end{array}$ \\
\cline { 3 - 5 } & & Sót sàng $0,08 \mathrm{~mm}$ & Sót sàng $0,045 \mathrm{~mm}$ & \\
\hline Xỉ lò cao Formosa & 0,053 & 0,65 & 2,045 & 4.150 \\
\hline
\end{tabular}

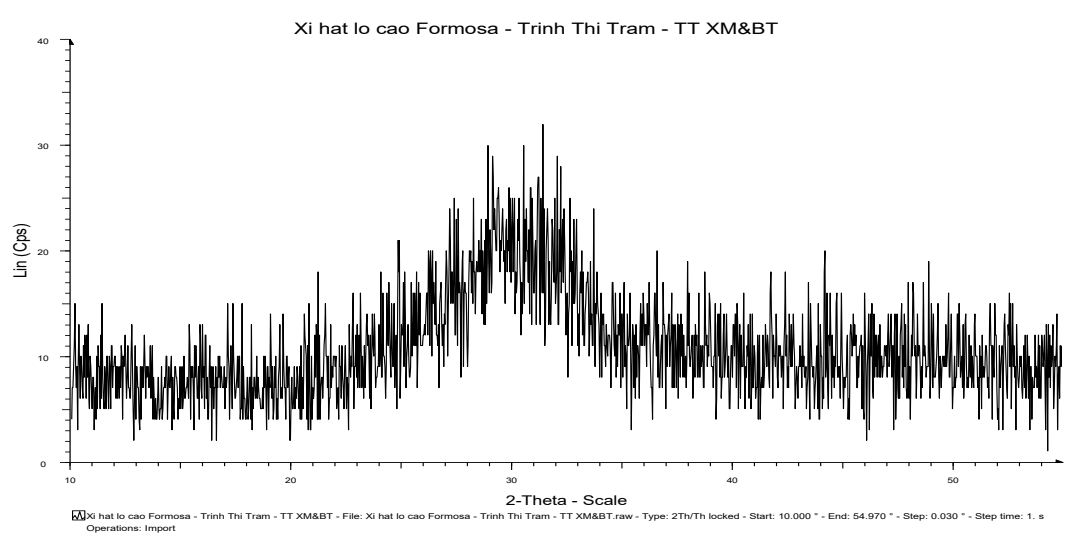

Hình 1. Biểu đồ thành phần khoáng của xỉ lò cao. 
Phân tích XRD của xỉ lò cao nhận được thành phần khoáng chủ yếu là pha vô định hình, với hàm lượng $99 \%$. Giản đồ phân tích XRD của xỉ lò cao được thể hiện trong Hình 1.

\subsection{Thach cao FGD}

Thạch cao FGD được lấy tại nhà máy nhiệt điện Nghi Sơn I. Các tính chất cơ bản của thạch cao FGD được đưa ra ở Bảng 5.

Bảng 5.

Các tính chất vật lý cơ bản của FGD.

\begin{tabular}{|c|c|c|c|}
\hline $\begin{array}{c}\text { Nguyên } \\
\text { vật liệu }\end{array}$ & Độ ẩm (\%) & $\begin{array}{c}\text { Độ mịn, sót sàng } \\
0,08 \mathrm{~mm}(\%)\end{array}$ & $\begin{array}{c}\text { Tỷ diện, theo pp } \\
\text { Blaine, } \mathrm{cm}^{2} / \mathrm{g}\end{array}$ \\
\hline $\begin{array}{c}\text { Thạch cao } \\
\text { FGD }\end{array}$ & 15,5 & 0,02 & 3.800 \\
\hline
\end{tabular}

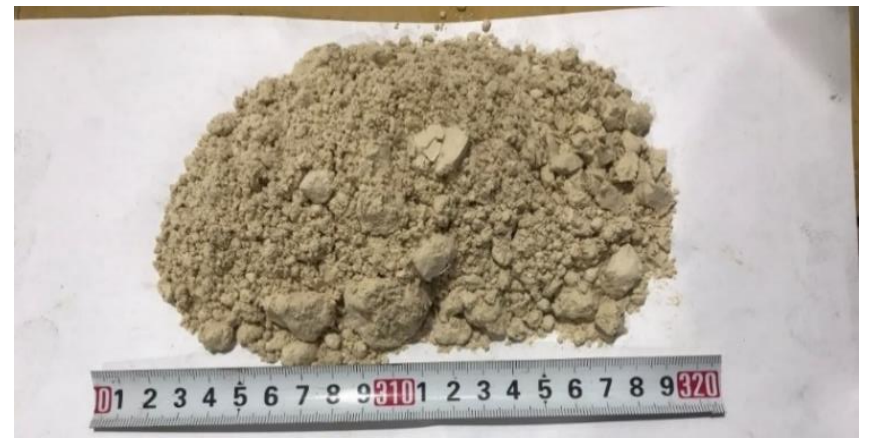

Hình 2. Thạch cao FGD Nghi Sơn.

Để phục vụ cho quá trình thử nghiệm, đề tài chế tạo thêm thạch cao FGD ở dạng hemihydrat và anhydrit, quy trình chuẩn bị như sau:

- Chuẩn bị dạng hemihydrat $\left(\mathrm{CaSO}_{4} \cdot 0,5 \mathrm{H}_{2} \mathrm{O}\right)$ : nung thạch cao FGD nguyên khai ở nhiệt độ $160^{\circ} \mathrm{C}$ trong vòng 3 giờ, lưu ở nhiệt độ $160^{\circ} \mathrm{C}$ là $2 \mathrm{~h}$, sau khi nung làm nguội tự nhiên trong lò. Bảo quản trong túi kín để tránh bị hút ẩm.

- Chuẩn bị dạng anhydrit $\left(\mathrm{CaSO}_{4}\right)$ : nung thạch cao FGD nguyên khai ở $500{ }^{\circ} \mathrm{C}$ trong vòng $5 \mathrm{~h}$, lưu ở nhiệt độ $500{ }^{\circ} \mathrm{C}$ là 2 giờ, sau đó làm nguội tự nhiên trong lò. Bảo quản trong túi kín.

Để kiểm tra thành phần khoáng của các mẫu sau khi chuẩn bị như trên, nhóm thực hiện sử dụng phương pháp phân tích XRD. Biểu đồ thành phần khoáng của 3 dạng tồn tại của thạch cao FGD thể hiện trong Hình 3 .

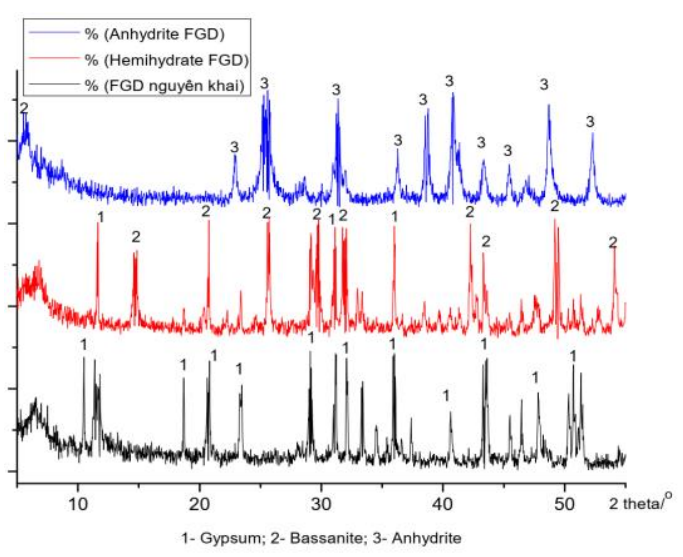

Hình 3. Phân tích XRD của 3 dạng thạch cao FGD sử dụng trong nghiên cứu.

Trên cơ sở cường độ các peak đặc trưng, tính toán tương đối bán định lượng các khoáng có mặt trong thạch cao FGD được thể hiện trong Bảng 6.

Từ biểu đồ thành phần khoáng (Hình 3) và bảng phân tích bán định lượng hàm lượng các khoáng (Bảng 6), có thể thấy rằng, khi chuẩn bị các dạng thạch cao FGD theo quy trình đã đưa ra ở trên có thể thu được đúng các dạng thạch cao FGD mong muốn để có thể sử dụng chế tạo các cấp phối thử nghiệm trong nghiên cứu.

\subsection{Cấp phối thử nghiệm}

Theo tiêu chuẩn BS EN 15753:2010+A1:2015 [3], xi măng siêu Sulfate có thành phần chính là xỉ lò cao với hàm lượng $\geq 75 \%, \mathrm{CaSO}_{4}$ (có thể sử dụng các dạng khác nhau) hàm lượng từ 5 - $20 \%$ với vai trò làm hóa chất hoạt hóa Sulfate, vôi hoặc xi măng hàm lượng từ 0 - $5 \%$ với vai trò làm chất hoạt hóa kiềm. Do đó, các cấp phối thử nghiệm sẽ được thiết kế dựa trên tiêu chuẩn này. Đồng thời cũng sẽ thiết kế cấp phối sử dụng các dạng và hàm lượng khác nhau của thạch cao FGD nhằm đánh giá ảnh hưởng của chúng tới tính chất của xi măng siêu Sulfate.

Từ biểu đồ thành phần khoáng (Hình 3) và bảng phân tích bán định lượng hàm lượng các khoáng (Bảng 6), có thể thấy rằng, khi chuẩn bị các dạng thạch cao FGD theo quy trình đã đưa ra ở trên có thể thu được đúng các dạng thạch cao FGD mong muốn để có thể sử dụng chế tạo các cấp phối thử nghiệm trong nghiên cứu.

\section{Bảng 6.}

Thành phần các khoáng trong các dạng thạch cao FGD.

\begin{tabular}{|c|l|c|c|c|c|c|c|}
\hline \multirow{2}{*}{ TT } & \multirow{2}{*}{ Tên dạng thạch cao } & \multicolumn{5}{|c|}{ Thành phần khoáng, \% khối lượng } \\
\cline { 3 - 7 } & & $\begin{array}{c}\text { Gypsum } \\
\mathrm{CaSO}_{4} \cdot 2 \mathrm{H}_{2} \mathrm{O}\end{array}$ & $\begin{array}{c}\text { Bassanite } \\
\mathrm{CaSO}_{4} \cdot 0,5 \mathrm{H}_{2} \mathrm{O}\end{array}$ & Anhydrite $\mathrm{CaSO}_{4}$ & \left.${\text { Quartz } \mathrm{SiO}_{2}}^{\text {Dolomite CaMg(CO) }}\right)_{3}$ & Pha vô định hình \\
\hline 1 & FGD nguyên khai & $\sim 87$ & - & - & $\sim 1$ & - \\
\hline 2 & FGD dạng hemihydrat & $\sim 12$ & $\sim 79$ & - & $\sim 1$ & $\sim 2$ \\
\hline 3 & FGD dạng khan hoàn toàn & - & $\sim 1$ & $\sim 90$ & $\sim 1$ & $\sim 6$ \\
\hline
\end{tabular}




\section{Bảng 7.}

Bảng cấp phối thử nghiệm.

\begin{tabular}{|c|c|c|c|c|c|c|}
\hline \multirow{2}{*}{ STT } & \multirow{2}{*}{ Tên mẫu } & \multicolumn{5}{|c|}{ Thành phần xi măng, \% theo khối lượng } \\
\hline & & Xi măng & Xỉ lò cao & FGD nguyên khai & FGD dạng hemihydrat & FGD khan \\
\hline 1 & 5C75S20G & 5 & 75 & 20 & & \\
\hline 2 & 5C85S10G & 5 & 85 & 10 & & \\
\hline 3 & $5 \mathrm{C} 75 \mathrm{~S} 20 \mathrm{H}$ & 5 & 75 & & 20 & \\
\hline 4 & $5 \mathrm{C} 85 \mathrm{~S} 10 \mathrm{H}$ & 5 & 85 & & 10 & \\
\hline 5 & 5C75S20A & 5 & 75 & & & 20 \\
\hline 6 & 5C85S10A & 5 & 85 & & & 10 \\
\hline
\end{tabular}

\subsection{Cấp phối thử nghiệm}

Theo tiêu chuẩn BS EN 15753:2010+A1:2015 [3], xi măng siêu Sulfate có thành phần chính là xỉ lò cao với hàm lượng $\geq 75 \%, \mathrm{CaSO}_{4}$ (có thể sử dụng các dạng khác nhau) hàm lượng từ $5-20 \%$ với vai trò làm hóa chất hoạt hóa Sulfate, vôi hoặc xi măng hàm lượng từ 0 - $5 \%$ với vai trò làm chất hoạt hóa kiềm. Do đó, các cấp phối thử nghiệm sẽ được thiết kế dựa trên tiêu chuẩn này. Đồng thời cũng sẽ thiết kế cấp phối sử dụng các dạng và hàm lượng khác nhau của thạch cao FGD nhằm đánh giá ảnh hưởng của chúng tới tính chất của xi măng siêu Sulfate.

\subsection{Phương pháp thử nghiệm}

Các phương pháp thử nghiệm sử dụng trong nghiên cứu này gồm:

- Phương pháp xác định lượng nước tiêu chuẩn, thời gian đông kết theo TCVN 6017:2015 [4];

- Phương pháp xác định cường độ xi măng theo TCVN 6016:2011 [1], tuy nhiên lượng nước yêu cầu được thử nghiệm theo TCVN 9501:2013 [2].

Các mẫu vữa xi măng nhằm thử nghiệm mức độ suy giảm cường độ trong các môi trường xâm thực Sulfate và nước biển cũng được chuẩn bị theo 2 tiêu chuẩn này, tuy nhiên môi trường ngâm mẫu là dung dịch $\mathrm{Na}_{2} \mathrm{SO}_{4} 5 \%$ đối với các mẫu được đánh giá độ bền Sulfate, trong nước biển nhân tạo đối với mẫu được đánh giá độ bền trong môi trường nước biển.

Thành phần của nước biển nhân tạo được thể hiện trong Bảng 8.

\section{Bảng 8.}

Thành phần chế tạo của nước biển nhân tạo.

\begin{tabular}{|c|c|c|}
\hline STT & Tên hóa chất & Tỷ lệ sử dụng, g/lit \\
\hline 1 & $\mathrm{NaCl}$ & 27,618 \\
\hline 2 & $\mathrm{MgCl}_{2}$ & 2,26 \\
\hline 3 & $\mathrm{MgSO}_{4}$ & 3,248 \\
\hline 4 & $\mathrm{CaCl}_{2}$ & 1,153 \\
\hline 5 & $\mathrm{KCl}$ & 0,721 \\
\hline
\end{tabular}

- Xác định độ co khô của vữa: theo TCVN 8824:2011 [5];
- Xác định nhiệt thủy hóa của xi măng ở độ tuổi 3, 7, 28 ngày theo TCVN 6070:2005 [6];

- Phân tích XRD của các mẫu trên máy chụp D8 seri 2 của hãng Bruker tại Trung tâm kiểm định, Viện VLXD;

- Phân tích hình dạng vi cấu trúc của mẫu bằng phương pháp SEM sử dụng kính Fe-SEM 4800 của Hitachi tại Viện Vệ sinh dịch tễ trung ương.

- Cách chế tạo mẫu hồ xi măng để chụp XRD và chụp SEM + Dùng cân kỹ thuật cân $200 \mathrm{~g}$ nước sau đó cho $500 \mathrm{~g}$ hỗn hợp chất kết dính (tỷ lệ $\mathrm{N} / \mathrm{HH}=0,4$ ), chính xác đến $0,1 \mathrm{~g}$, cho vào cối trộn.

+ Trộn nước và xi măng theo quy trình thử nghiệm nước tiêu chuẩn theo TCVN 6016:2011.

+ Sau khi trộn, cho mẫu vào khay nhựa chia ngăn, rung trên bàn rung trong vòng 45 giây, sau đó cho vào phòng dưỡng ẩm, dưỡng ẩm trong vòng $24 \mathrm{~h}$.

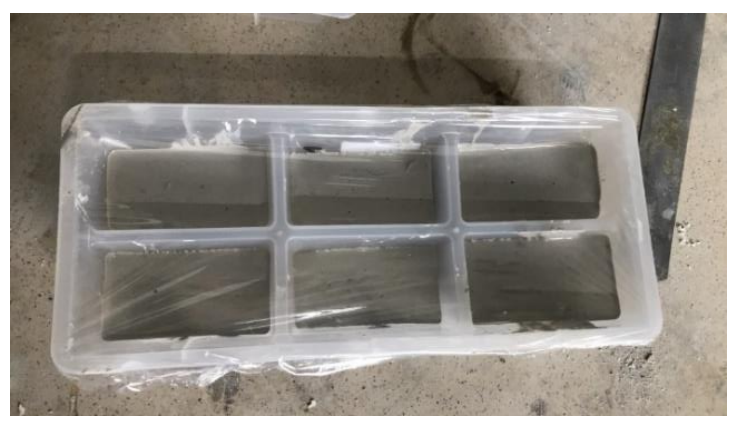

Hình 4. Chuẩn bị mẫu thử nghiệm chụp SEM và XRD.

+ Sau 24h, mẫu được tách khỏi khuôn, bảo dưỡng trong nước ở điều kiện dưỡng hộ tiêu chuẩn, nhiệt độ phòng dưỡng hộ duy trì ở $27 \pm 2$ ${ }^{\circ} \mathrm{C}$, độ ẩm $\geq 95 \%$.

\section{Kết quả nghiên cứu và thảo luận}

3.1 Ảnh hưởng của các dạng thạch cao FGD tới lượng nước tiêu chuẩn và thời gian đông kết của xi măng siêu Sulfate

Nước tiêu chuẩn và thời gian đông kết của mẫu được thể hiện trong Bảng 9.

Từ Bảng 9, ta có đồ thị thể hiện lượng nước tiêu chuẩn và thời gian đông kết tới dạng của thạch cao FGD được thể hiện trong Hình 5 và 6 . 
Bảng 9.

Nước tiêu chuẩn, thời gian đông kết của xi măng.

\begin{tabular}{|c|c|c|c|c|}
\hline STT & Tên mẫu & $\begin{array}{c}\text { Nước tiêu } \\
\text { chuẩn, } \%\end{array}$ & $\begin{array}{c}\text { TGBĐ ĐK, } \\
\text { min }\end{array}$ & $\begin{array}{c}\text { TG KT } \\
\text { Đk, min }\end{array}$ \\
\hline 1 & $\begin{array}{c}\text { OPC Hoàng } \\
\text { Long }\end{array}$ & 27,15 & 105 & 150 \\
\hline 2 & 5C75S20G & 32,5 & 300 & 435 \\
\hline 3 & 5C85S10G & 33,0 & 290 & 380 \\
\hline 4 & 5C75S20H & 36,0 & 210 & 420 \\
\hline 5 & 5C85S10H & 35,0 & 285 & 505 \\
\hline 6 & 5C75S20A & 32,0 & 220 & 330 \\
\hline 7 & 5C85S10A & 31,0 & 250 & 370 \\
\hline
\end{tabular}

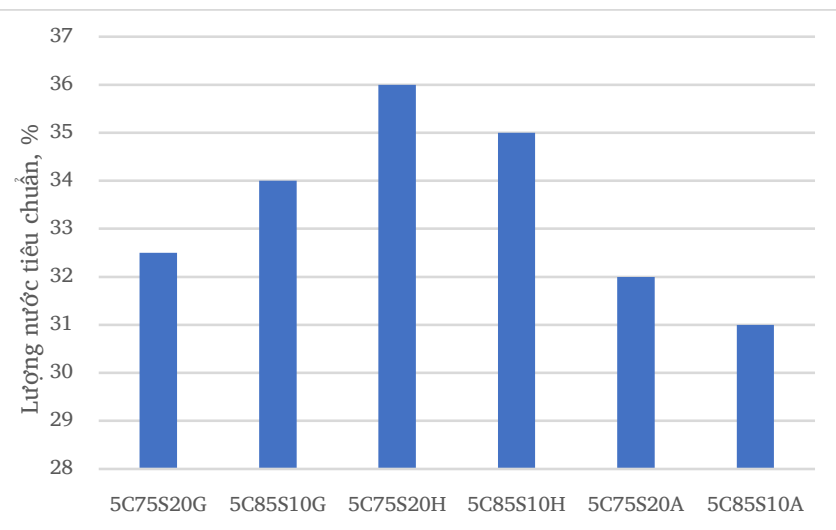

Hình 5. Nước tiêu chuẩn của các xi măng.

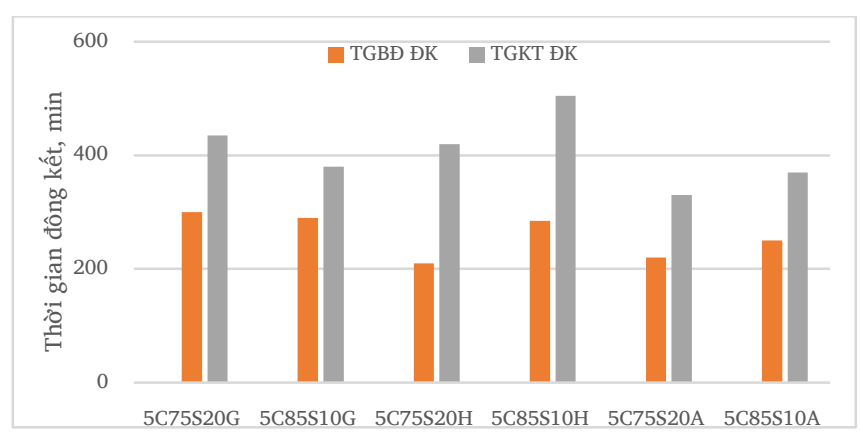

Hình 6. Thời gian đông kết của các xi măng.
- Lượng nước tiêu chuẩn của các mẫu sử dụng thạch cao dạng $\mathrm{CaSO}_{4} \cdot 0,5 \mathrm{H}_{2} \mathrm{O}$ cao nhất, sau đó là các mẫu với sử dụng thạch cao tự nhiên và thạch cao khan. Điều này có thể giải thích là do thạch cao $\mathrm{CaSO}_{4} \cdot 0,5 \mathrm{H}_{2} \mathrm{O}$ dễ dàng phản ứng với nước để tạo ra $\mathrm{CaSO}_{4} \cdot 2 \mathrm{H}_{2} \mathrm{O}$ theo phương trình phản ứng như sau:

$$
\mathrm{CaSO}_{4} \cdot 0,5 \mathrm{H}_{2} \mathrm{O}+\mathrm{H}_{2} \mathrm{O} \rightarrow \mathrm{CaSO}_{4} \cdot 2 \mathrm{H}_{2} \mathrm{O}
$$

- Chênh lệch giữa thời gian bắt đầu đông kết và kết thúc đông kết của các nhóm mẫu đều lớn hơn với với mẫu xi măng OPC đối chứng, trong đó nhóm mẫu sử dụng thạch cao dạng hemihydrat là chênh lệch nhiều nhất (chênh lệch 210 - 220 phút).

\section{2. Ảnh hưởng của các dạng thạch cao FGD tới cường độ nén của xi măng siêu Sulfate trong các môi trường xâm thực}

Mẫu vữa được chế tạo theo tiêu chuẩn theo TCVN 6016:2011, nhưng với nhu cầu nước được thể theo TCVN 9501:2013 để đảm bảo độ chảy khống chế của vữa từ $115-125 \mathrm{~mm}$. Bảng 10 thể hiện giá trị nhu cầu nước, độ chảy và tỷ lệ nước/xi măng để chế tạo cường độ.

Bảng 10.

Nhu cầu nước, độ chảy và tỷ lệ N/XM.

\begin{tabular}{|c|c|c|c|c|}
\hline STT & Tên mẫu & $\begin{array}{c}\text { Lượng nước } \\
\text { yêu cầu, } \mathbf{~ m l}\end{array}$ & $\begin{array}{c}\text { Độ chảy của } \\
\text { vữa, cm }\end{array}$ & $\begin{array}{c}\text { Tỷ lệ } \\
\text { Nước/XM }\end{array}$ \\
\hline 1 & 5C75S20G & 205 & 12,2 & 0,46 \\
\hline 2 & 5 C85S10G & 200 & 12,0 & 0,44 \\
\hline 3 & $5 C 75 S 20 H$ & 245 & 11,7 & 0,54 \\
\hline 4 & 5C85S10H & 237 & 12,4 & 0,53 \\
\hline 5 & 5C75S20A & 203 & 11,8 & 0,45 \\
\hline 6 & 5C85S10A & 200 & 11,9 & 0,44 \\
\hline
\end{tabular}

\section{Nhận xét:}

- Nhu cầu nước để chế tạo cường độ vữa xi măng của nhóm mẫu sử dụng FGD dạng hemihydrat cao hơn 2 nhóm mẫu sử dụng thạch cao FGD nguyên khai và FGD dạng anhydrit. Điều này cũng tương đồng với lượng nước tiêu chuẩn trong thử nghiệm độ dẻo tiêu chuẩn (Bảng 9).

- Nhu cầu nước của nhóm mẫu sử dụng FGD nguyên khai gần như tương đương với nhóm mẫu sử dụng FGD dạng anhydrit.

Các mẫu được ngâm trong 03 môi trường: nước thường, dung dịch Sulfate và nước biển để đánh giá độ bền lâu ở các tuổi $2,3,7,28$, 60 và 90 ngày, kết quả được thể hiện trong Bảng 11, 12, 13.

\section{Nhận xét:}

\section{Bảng 11.}

Cường độ nén của các mẫu ngâm trong nước thường.

\begin{tabular}{|c|c|c|c|c|c|c|c|}
\hline STT & Tên mẫu & R2d, MPa & R3d, MPa & R7d, MPa & R28d, MPa & R60d, MPa & R90d, MPa \\
\hline 1 & 5C75S20G & 9,96 & 13,60 & 20,89 & 25,30 & 23,77 & 27,28 \\
\hline 2 & 5C85S10G & 10,57 & 14,08 & 17,32 & 25,90 & 25,10 & 24,99 \\
\hline 4 & $5 \mathrm{C} 85 \mathrm{~S} 10 \mathrm{H}$ & 9,05 & 14,86 & 20,12 & 30,79 & 45,98 & 47,27 \\
\hline 5 & 5C75S20A & 17,20 & 18,25 & 32,23 & 46,87 & 46,04 & 49,2 \\
\hline
\end{tabular}


Bảng 12.

Cường độ nén của các mẫu ngâm trong dung dịch Sulfate và chênh lệch cường độ so với ngâm nước thường.

\begin{tabular}{|c|c|c|c|c|c|c|c|c|c|c|c|}
\hline TT & Tên mẫu & $\begin{array}{r}\text { R2d, } \\
\text { MPa }\end{array}$ & $\begin{array}{c}\text { Chênh } \\
\text { lệch, \% }\end{array}$ & $\begin{array}{r}\text { R7d, } \\
\text { MPa }\end{array}$ & $\begin{array}{c}\text { Chênh } \\
\text { lệch, \% }\end{array}$ & $\begin{array}{c}\text { R28d, } \\
\text { MPa }\end{array}$ & $\begin{array}{c}\text { Chênh } \\
\text { lệch, \% }\end{array}$ & $\begin{array}{c}\text { R60d, } \\
\text { MPa }\end{array}$ & $\begin{array}{c}\text { Chênh } \\
\text { lệch, \% }\end{array}$ & $\begin{array}{c}\text { R90d, } \\
\text { MPa }\end{array}$ & $\begin{array}{c}\text { Chênh } \\
\text { lệch, \% }\end{array}$ \\
\hline 1 & 5 C75S20G & 8,16 & $-18,07$ & 13,09 & $-37,34$ & 20,97 & $-17,11$ & 24,65 & 3,70 & 26,47 & $-2,97$ \\
\hline 2 & 5 C85S10G & 12,16 & 15,04 & 17,46 & 0,81 & 26,91 & 3,90 & 29,24 & 16,49 & 32,87 & 31,53 \\
\hline 3 & 5 C75S20H & 8,74 & $-8,00$ & 20,13 & $-21,73$ & 44,5 & 14,57 & 44,44 & 17,01 & 26,53 & $-41,78$ \\
\hline 4 & 5 C85S10H & 11,66 & 28,84 & 22,03 & 9,49 & 35,55 & 15,46 & 46,99 & 2,20 & 48,52 & 2,64 \\
\hline 5 & 5 C75S20A & 14,18 & $-17,56$ & 30,37 & $-5,77$ & 45,35 & $-3,24$ & 46,23 & 0,41 & 46,53 & $-5,43$ \\
\hline 6 & 5C85S10A & 12,43 & $-21,48$ & 22,82 & $-8,57$ & 32,77 & $-7,38$ & 37,43 & 1,60 & 37,17 & $-10,35$ \\
\hline
\end{tabular}

Bảng 13.

Cường độ nén của các mẫu ngâm trong nước biển và chênh lệch cường độ so với ngâm nước thường.

\begin{tabular}{|c|c|c|c|c|c|c|c|c|c|c|c|}
\hline TT & Tên mẫu & $\begin{array}{r}\text { R2d, } \\
\text { MPa }\end{array}$ & $\begin{array}{c}\text { Chênh } \\
\text { lệch, \% }\end{array}$ & $\begin{array}{r}\text { R7d, } \\
\text { MPa }\end{array}$ & $\begin{array}{c}\text { Chênh } \\
\text { lệch, \% }\end{array}$ & $\begin{array}{c}\text { R28d, } \\
\text { MPa }\end{array}$ & $\begin{array}{c}\text { Chênh } \\
\text { lệch, \% }\end{array}$ & $\begin{array}{c}\text { R60d, } \\
\text { MPa }\end{array}$ & $\begin{array}{c}\text { Chênh } \\
\text { lệch, \% }\end{array}$ & $\begin{array}{c}\text { R90d, } \\
\text { MPa }\end{array}$ & $\begin{array}{c}\text { Chênh } \\
\text { lệch, \% }\end{array}$ \\
\hline 1 & 5 C75S20G & 8,16 & $-18,07$ & 13,09 & $-37,34$ & 20,97 & $-17,11$ & 24,65 & 3,70 & 26,47 & $-2,97$ \\
\hline 2 & 5 C85S10G & 12,16 & 15,04 & 17,46 & 0,81 & 26,91 & 3,90 & 29,24 & 16,49 & 32,87 & 31,53 \\
\hline 3 & 5 C75S20H & 8,74 & $-8,00$ & 20,13 & $-21,73$ & 44,5 & 14,57 & 44,44 & 17,01 & 26,53 & $-41,78$ \\
\hline 4 & 5 C85S10H & 11,66 & 28,84 & 22,03 & 9,49 & 35,55 & 15,46 & 46,99 & 2,20 & 48,52 & 2,64 \\
\hline 5 & 5 C75S20A & 14,18 & $-17,56$ & 30,37 & $-5,77$ & 45,35 & $-3,24$ & 46,23 & 0,41 & 46,53 & $-5,43$ \\
\hline 6 & 5C85S10A & 12,43 & $-21,48$ & 22,82 & $-8,57$ & 32,77 & $-7,38$ & 37,43 & 1,60 & 37,17 & $-10,35$ \\
\hline
\end{tabular}

Từ Bảng 11, 12, 13 ta có đồ thị quan hệ giữa ngày dưỡng hộ và cường độ được thể hiện trong Hình 7 và Hình 8.

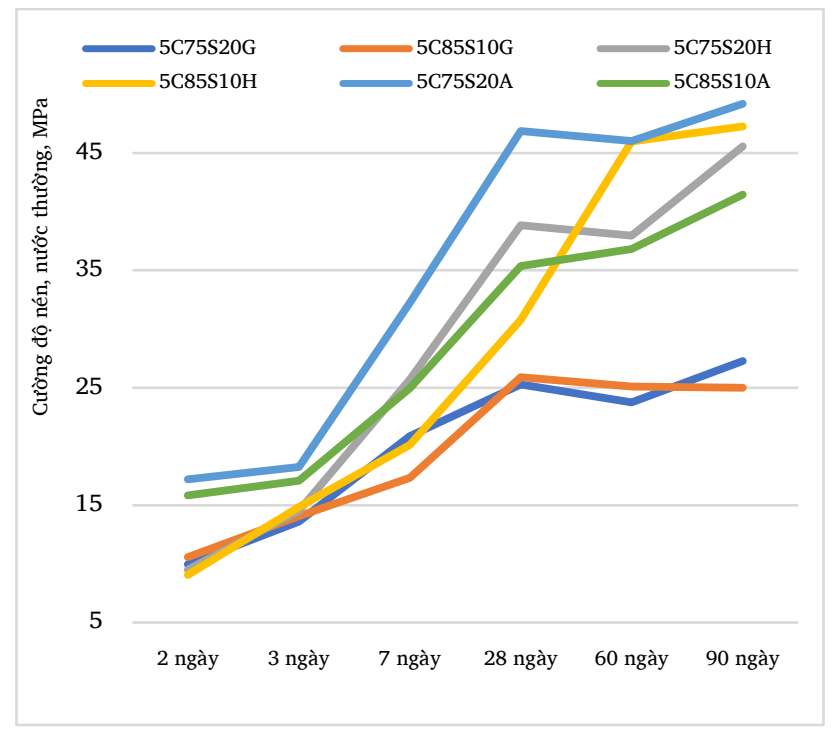

Hình 7.a. Cường độ của đá xi măng ngâm trong nước thường ở các ngày tuổi.

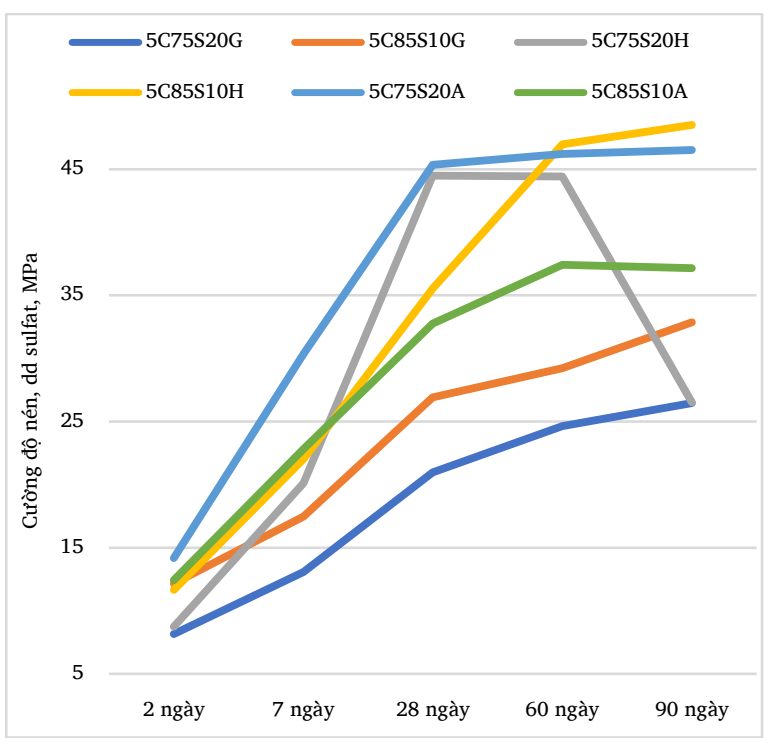

Hình 8.b. Cường độ của đá xi măng ngâm trong dung dịch Sulfate ở các ngày tuổi. 


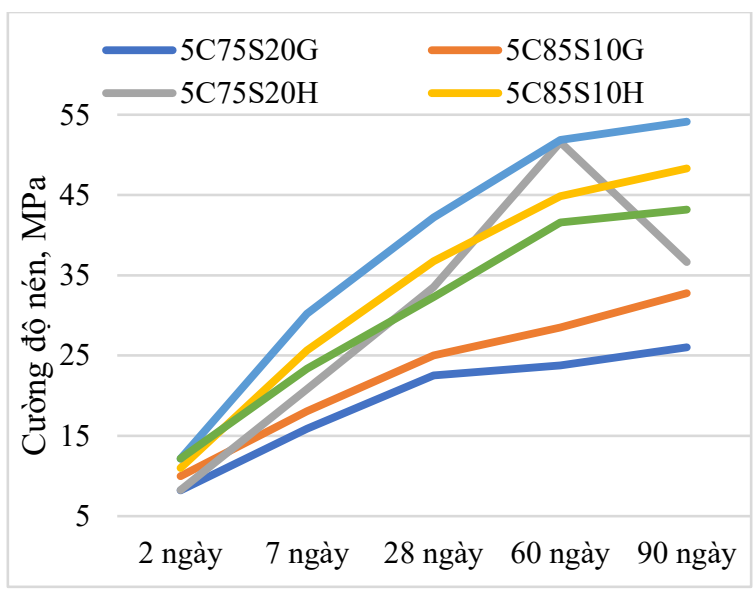

Hình 7.c. Cường độ của đá xi măng ngâm trong nước biển ở các ngày tuổi.

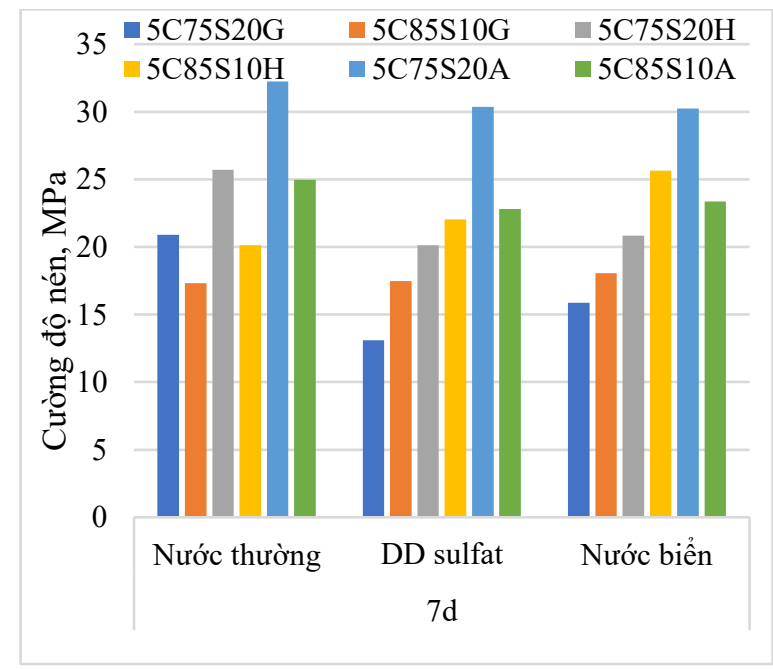

Hình 8.b. Cường độ nén của đá xi măng bảo dưỡng trong 3 môi trường khác nhau ở tuổi 7 ngày.

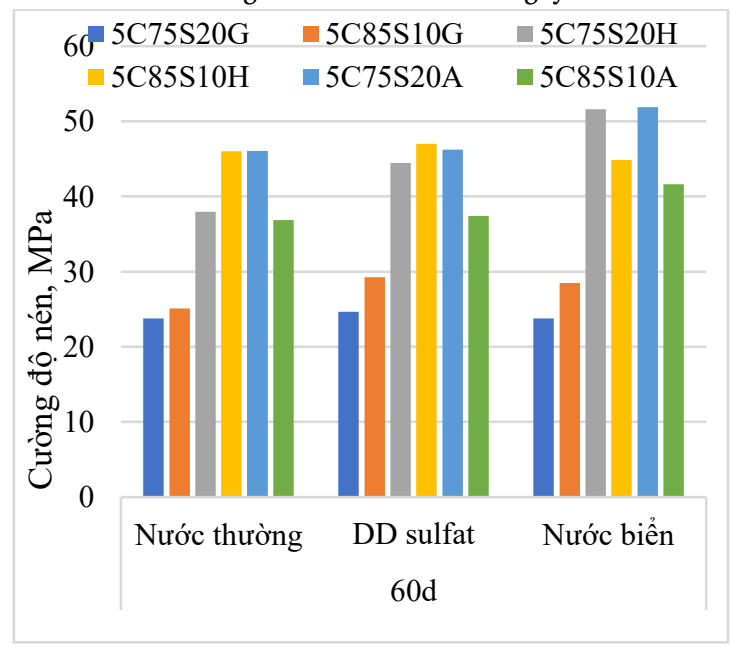

Hình 8.d. Cường độ nén của đá xi măng bảo dưỡng trong 3 môi trường ở tuổi 60 ngày.

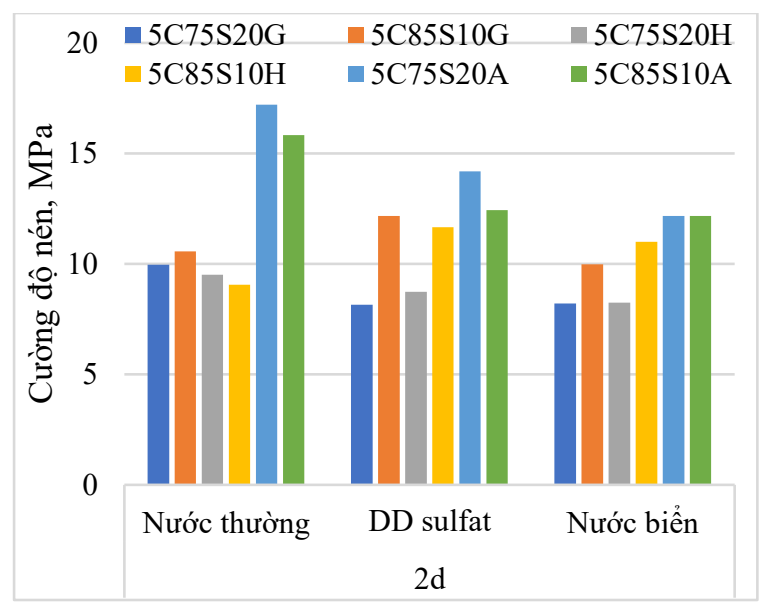

Hình 8.a. Cường độ nén của đá xi măng bảo dưỡng trong 3 môi trường ở tuổi 2 ngày.

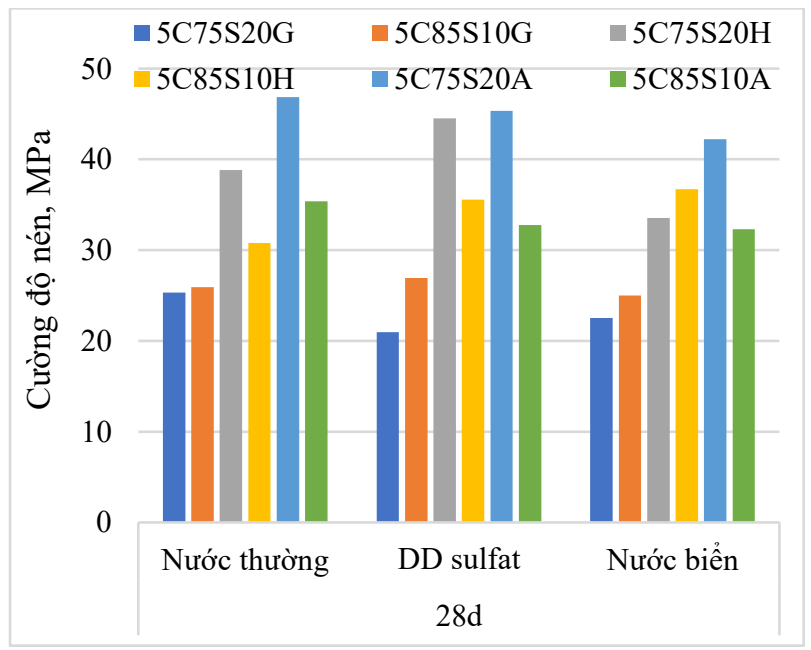

Hình 89.c. Cường độ nén của đá xi măng bảo dưỡng trong 3 môi trường khác nhau ở tuổi 28 ngày.

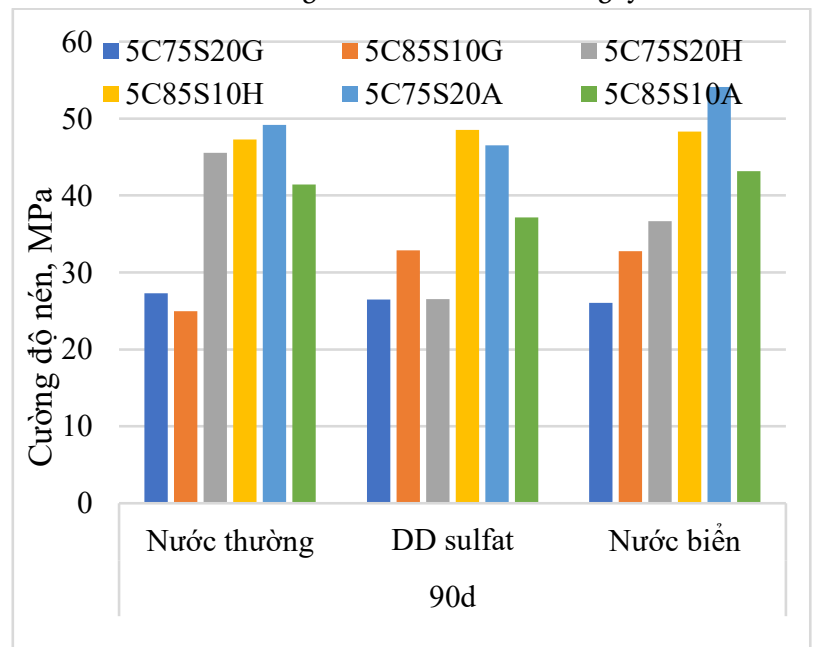

Hình 8.e. Cường độ nén của đá xi măng bảo dưỡng trong 3 môi trường ở tuổi 90 ngày. 


\section{Nhận xét:}

- Mẫu vữa xi măng ngâm trong môi trường nước thường:

+ Cường độ tăng khi tăng thời gian ngâm mẫu vữa xi măng.

+ Các mẫu vữa xi măng sử dụng thạch cao FGD nguyên khai ở tuổi 28 ngày không đáp ứng yêu cầu của tiêu chuẩn BS EN 15753:2010 + A1:2015.

+ Các mẫu vữa xi măng còn lại sử dụng FGD dạng hemihydrats và anhydrat đều đáp ứng loại 32,5 N, riêng cấp phối 5C75S20A thỏa mãn loại 42,5 N theo phân loại của BS EN 15753:2010 + A1:2015. - Mẫu vữa xi măng ngâm trong dung dịch Sulfate:

+ Cường độ hầu hết tăng khi tăng thời gian ngâm mẫu, tuy nhiên mẫu sử dụng 20 \% FGD dạng hemihydart (5C75S20H) thì cường độ sau 90 ngày thấp hơn cường độ 60 ngày. Điều này có thể do trong dung dịch Sulfate, nồng độ Sulfate dư nên kết tủa ettringite nhiều hơn và bám vào bề mặt của hạt xỉ. Do hiệu ứng nở thể tích của ettringite, vữa xi măng $5 \mathrm{C} 75 \mathrm{~S} 20 \mathrm{H}$ sẽ bị nứt, làm giảm độ bền. Hiện tượng này có thể do hemihydrat hoạt tính hơn so với dạng tự nhiên hoặc dạng anhydrit nên đã bị hòa tan đáng kể ra môi trường để bão hòa nồng độ Sulfate dẫn đến cường độ mẫu giảm.

+ Ở tuổi sớm (2 ngày, 7 ngày và 28 ngày), hầu hết các mẫu ngâm trong dung dịch Sulfate có cường độ thấp hơn so với mẫu ngâm trong nước thường, tuy nhiên ở các tuổi sau, từ 60 ngày đến 90 ngày, cường độ các mẫu ngâm trong dung dịch Sulfate hầu như cao hơn các mẫu ngâm trong nước thường (trừ 2 cấp phối 5C75S20H, 5C85S10A ở tuổi 90 ngày).

- Mẫu vữa xi măng ngâm trong nước biển nhân tạo:

+ Cường độ hầu hết tăng khi tăng thời gian ngâm mẫu. Tương tự như trong môi trường Sulfate mẫu sử dụng $20 \%$ FGD dạng hemihydart $(5 \mathrm{C} 75 \mathrm{~S} 20 \mathrm{H})$ cường độ ở 90 ngày thấp hơn cường độ 60 ngày.

+ Ở tuổi 2 ngày, hầu hết các ngâm trong dung dịch Sulfate có cường độ thấp hơn so với mẫu ngâm trong nước thường, tuy nhiên ở các tuổi sau, từ 7 ngày đến 90 ngày, cường độ các mẫu ngâm trong nước biển hầu như cao hơn các mẫu ngâm trong nước thường và dung dịch Sulfate.

Điều này giải thích là do:

+ Trong môi trường nước thường, quá trình thủy hóa của SSC tàng của xỉ.[7] Khi SSC được trộn với nước, trước tiên Sulfate và clanhke hòa tan trong hệ, tạo thành $\mathrm{OH}^{-}, \mathrm{Ca}^{2+}, \mathrm{SO}_{4}{ }^{2-}$ và một lượng nhỏ $\mathrm{Al}^{3+}, \mathrm{Si}^{4+} \ldots$ Sau đó, gel canxi silicat ngậm nước (C-S-H) và gel canxi aluminat ngậm nước (C-A-H) được hình thành.

$$
\begin{aligned}
& \mathrm{Ca}(\mathrm{OH})_{2}+\mathrm{SiO}_{2} \rightarrow \mathrm{C}-\mathrm{S}-\mathrm{H} \text { (gel) (4) } \\
& \mathrm{Ca}(\mathrm{OH})_{2}+\mathrm{Al}_{2} \mathrm{O}_{3} \rightarrow \text { C-A-H (gel) (5) }
\end{aligned}
$$

Một tỷ lệ nhỏ xi măng poóc lăng ban đầu sẽ hydrat hóa, cung cấp canxi hydroxit $(\mathrm{CH})$, thúc đẩy quá trình hòa tan xỉ. Các ion nhôm, canxi và silic hòa tan từ xỉ phản ứng với canxi sunfat (C\$) được bổ sung tạo thành pha ettringite $\left(\mathrm{C}_{6} \mathrm{~A} \$_{3} \mathrm{H}_{32}\right)$ và canxi silicat hydrat $(\mathrm{C}-\mathrm{S}$ $\mathrm{H}$ ), như được minh họa trong phương trình (6) [8]. Sản phẩm thủy hóa chính là Ettringte.

$$
\mathrm{C}_{5} \mathrm{~S}_{3} \mathrm{~A}+\mathrm{CH}+\mathrm{C} \$+34 \mathrm{H} \rightarrow \mathrm{C}_{6} \mathrm{~A}_{3} \mathrm{H}_{32}+3 \mathrm{CSH}(6)
$$

+ Trong môi trường Sulfate, nước biển, các ion $\mathrm{Ca}^{2+,} \mathrm{SO}_{4}{ }^{2}, \mathrm{Cl}^{-}$từ dung dịch tiếp tục phản ứng với các thành phần có trong xỉ. Nước biển có nồng độ ion $\mathrm{Cl}^{-}$cao nên $\mathrm{Cl}^{-}$sẽ phản ứng với các sản phẩm thủy hóa AFt trong hỗn hợp tạo nên các tinh thể Friedel's salt (họ Cl-AFt) trong các lỗ rỗng C-S-H làm cấu trúc đá xi măng đặc chắc theo thời gian, giảm kích thước lỗ rỗng nên làm tăng cường độ đá xi măng ở tuổi dài ngày.

Do đó, có thể thấy rằng, xi măng siêu Sulfate sử dụng thạch cao FGD bền trong môi trường Sulfate và nước biển.

\subsection{Vi cấu trúc và thành phần khoáng của đá xi măng}

Lựa chọn 03 mẫu làm đại diện cho 3 dạng thạch cao FGD là: 5C85S10G, 5C85S10H, 5C75S20A để thử nghiệm các đặc tính của hồ xi măng gồm: phân tích vi cấu trúc (SEM), phân tích thành phần khoáng (XRD).

Các mẫu hồ xi măng được chuẩn bị theo mục 2.5, sau đó bảo dưỡng tới tuổi thử nghiệm. Mẫu hồ xi măng được dưỡng hộ đến 3 và 28 ngày được xác định thành phần khoáng (XRD) và vi cấu trúc (SEM)

Kết quả chụp vi cấu và thành phần khoáng của đá xi măng ở 3 và 28 ngày được thể hiện trong Hình $9,10$.

Từ kết quả phân tích XRD xác định bán định lượng hàm lượng các khoáng tồn tại trong đá xi măng ở tuổi 3 và 28 ngày được thể hiện trong Bảng 14.

dựa trên hiệu ứng kích thích của kiềm và Sulfate đối với hoạt tính tiềm

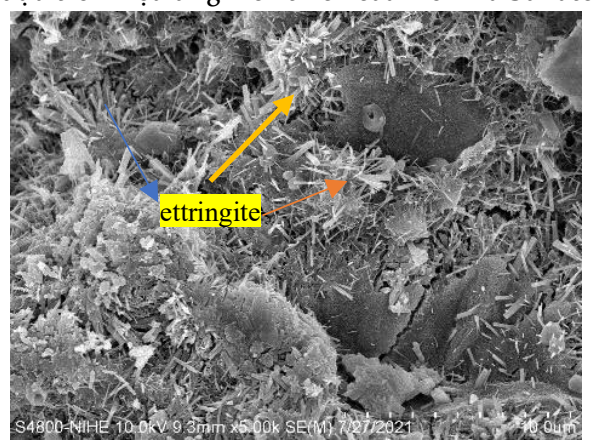

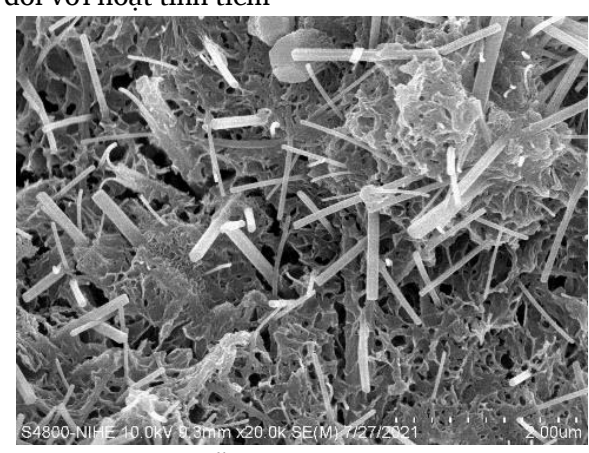

Mẫu 5C85S10G - 3d

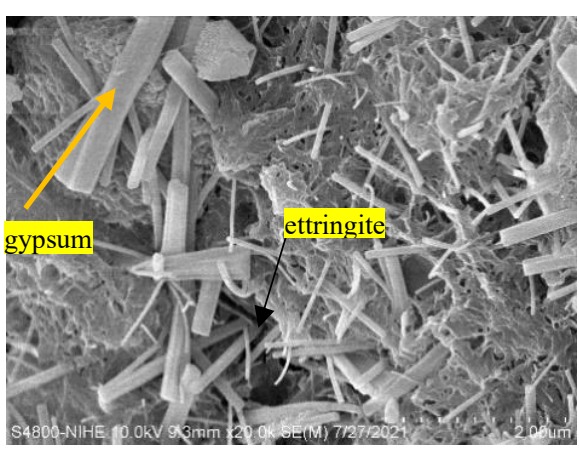



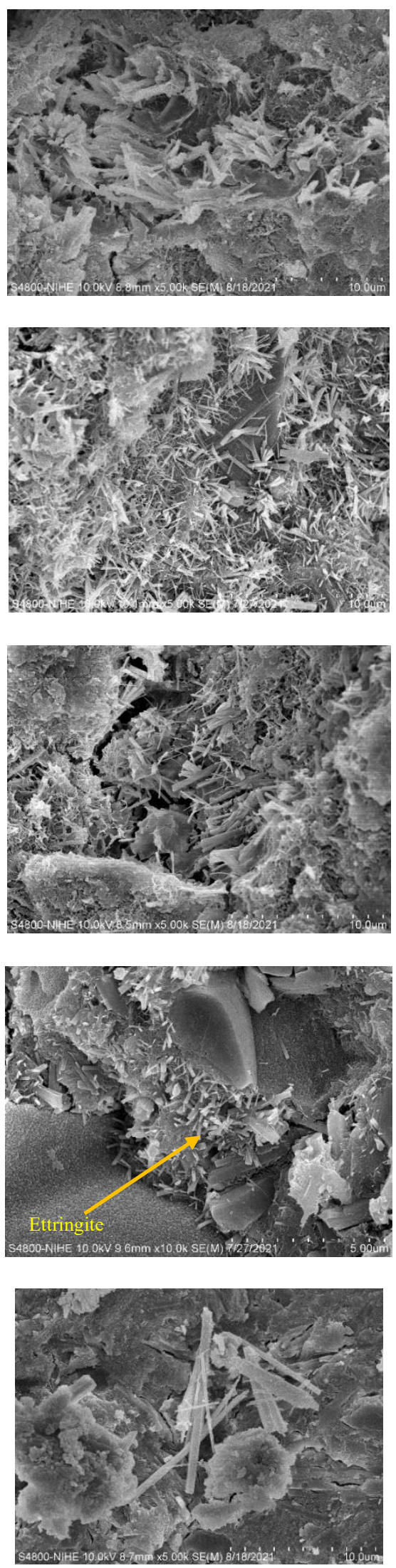

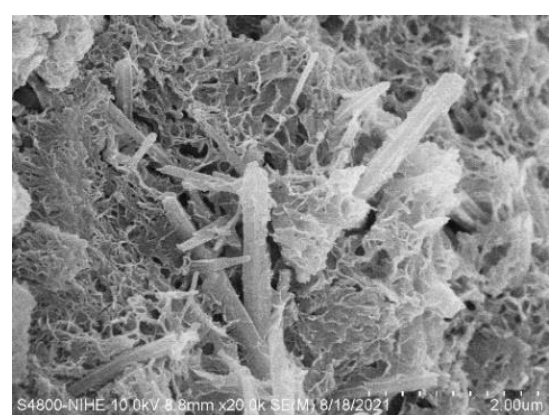

\section{Mẫu 5C85S10G - 28 d}

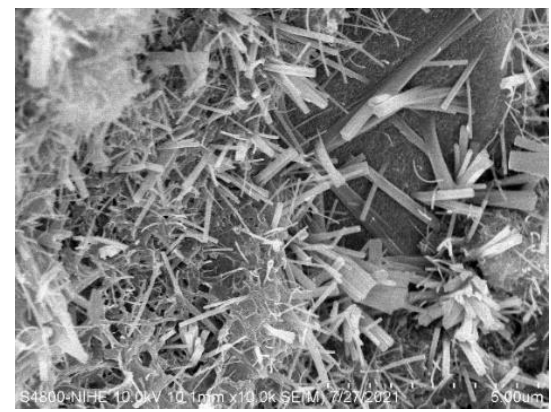

Mẫu 5C85S10H - 3 d

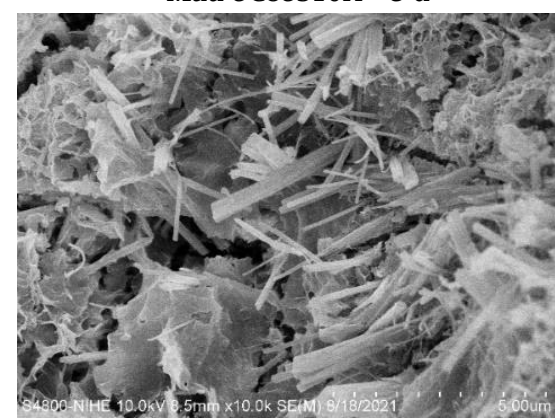

Mẫu 5C85S10H - 28d

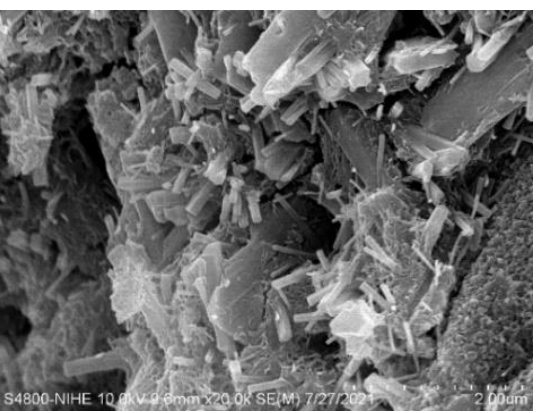

Mẫu 5C75S10A - 3d

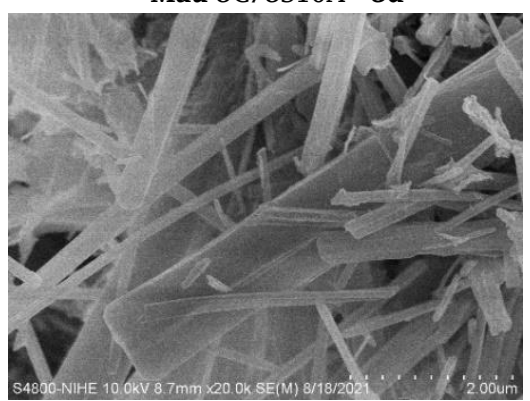

Mẫu 5C75S10A -28 d
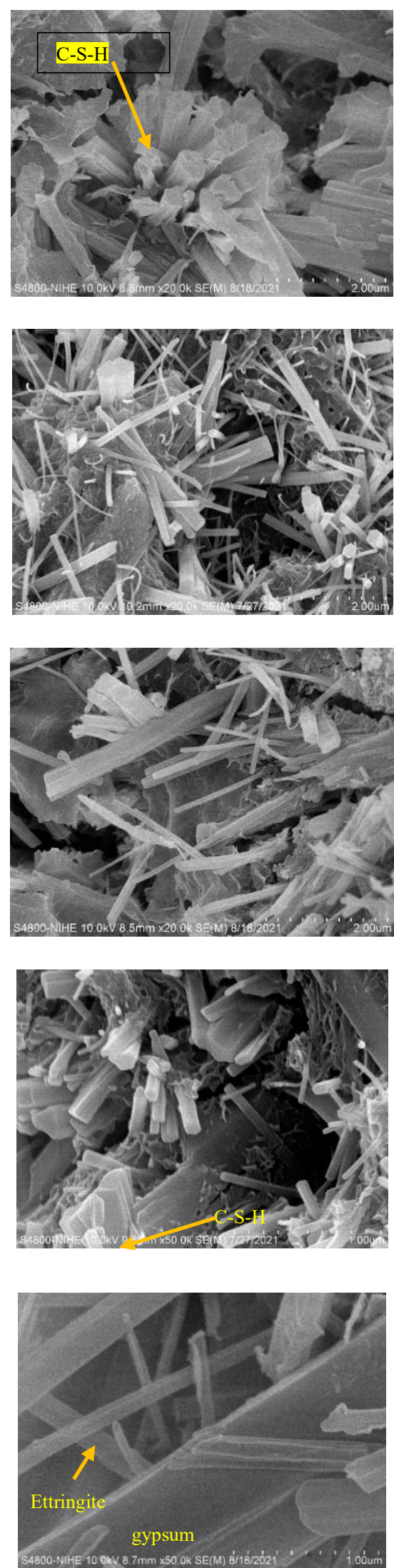

Hình 9. Vi cấu trúc của đá xi măng ở 3 và 28 ngày tuổi ngâm trong nước thường. 


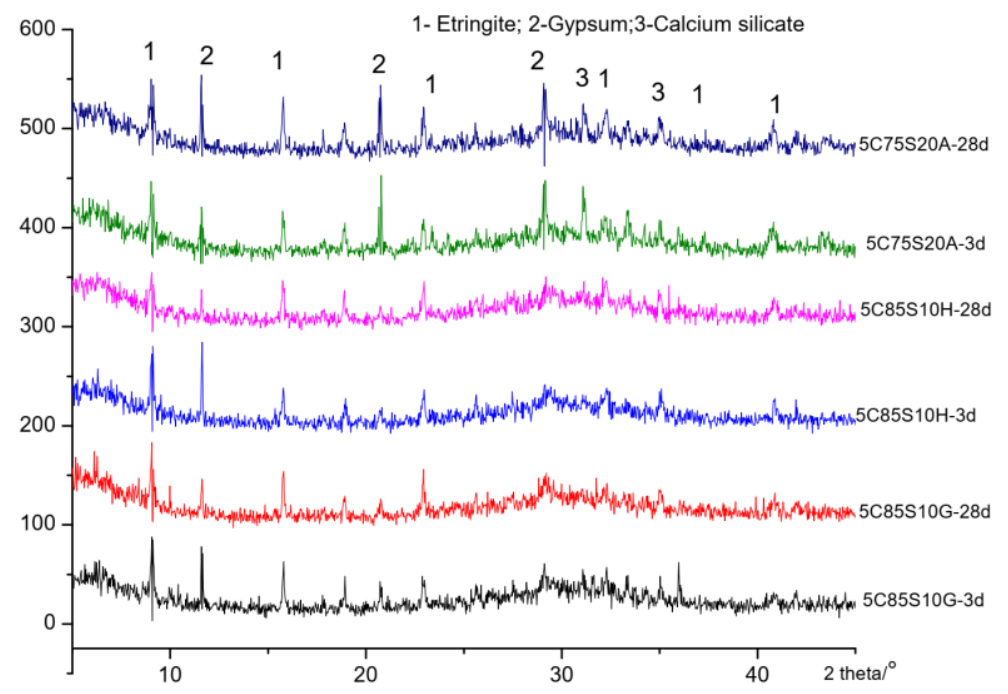

Hình 10. Phân tích XRD của đá xi măng ở tuổi 3, 28 ngày ngâm trong nước thường.

Bảng 14.

Thành phần các khoáng đá xi măng ở tuổi 3, 28 ngày ngâm trong nước thường.

\begin{tabular}{|l|c|c|c|c|c|}
\hline \multirow{2}{*}{ Tên mẫu xi măng } & \multicolumn{5}{|c|}{ Thành phần khoáng, \% khối lượng } \\
\cline { 2 - 6 } & Ettringite & Gypsum & Calcium Silicate & \multirow{2}{*}{ Larnite } & \multirow{2}{*}{ Pha vô định hình } \\
\hline 5C85S10G-3d & 16 & 10 & 16 & 12 & 46 \\
\hline 5C85S10G-28d & 19 & 7 & 13 & 17 & 54 \\
\hline 5C85S10H-3d & 17 & 9 & 13 & 13 & 43 \\
\hline 5C85S10H-28d & 16 & 4 & 12 & 10 & 54 \\
\hline 5C75S20A-3d & 19 & 23 & 10 & 12 & \\
\hline 5C75S20A-28d & 19 & 12 & & & \\
\hline
\end{tabular}

\section{Nhận xét:}

- Kết quả phân tích thành phần khoáng và vi cấu trúc của đá xi măng sử dụng 03 dạng của thạch cao khá tương đồng nhau. Các khoáng chủ yếu có mặt trong đá xi măng là ettringite (mảnh, nhỏ, tinh thể hình lăng trụ có vân), gypsum (đơn tà, tinh thể lớn kéo dài hình lăng trụ) và C-S-H (dạng tấm, xếp lớp).

- Các khoáng ở tuổi 3, 28 ngày có sự thay đổi về hàm lượng các khoáng gypsum, chứng tỏ khoáng gypsum trong thạch cao vẫn tiếp tục tan ra để phản ứng với thành phần vô định hình trong xỉ để tạo nên các

\section{Bảng 15.}

Nhiệt thủy hóa của xi măng.

\begin{tabular}{|c|c|c|c|c|}
\hline \multirow{2}{*}{ STT } & \multirow{2}{*}{ Tên mẫu } & \multicolumn{3}{|c|}{ Nhiệt thủy hóa ở các tuổi, cal/g } \\
\hline & & H3 & H7 & H28 \\
\hline 1 & 5C85S10G & 20,40 & 29,45 & 33,24 \\
\hline 3 & 5C75S20A & 31,17 & 40,64 & 61,66 \\
\hline \multicolumn{2}{|c|}{ Yêu cầu của BS EN 15753:2010 + A1:2015 } & - & Max 52,55 & - \\
\hline
\end{tabular}

sản phẩm thủy hóa ở tuổi dài ngày, góp phần vào tăng cường độ của đá xi măng.

3.4. Ảnh hưởng của các dạng thạch cao FGD tới nhiệt thủy hóa và độ co khô của xi măng

Lựa chọn 3 mẫu làm đại diện cho 3 dạng thạch cao FGD là: 5C85S10G, 5C85S10H, 5C75S20A để thử nghiệm quá trình thủy hóa và độ co khô của xi măng. Kết quả thử nghiệm được thể hiện trong Bảng 15 và Hình 14, và Bảng 16 và Hình 15. 
Bảng 16.

Độ co khô của xi măng.

\begin{tabular}{|c|l|c|c|c|c|}
\hline \multirow{2}{*}{ STT } & \multirow{2}{*}{ Tên mâu } & \multicolumn{4}{|c|}{ Độ co khô, \% } \\
\cline { 3 - 6 } & & 7 ngày & 14 ngày & 21 ngày & 28 ngày \\
\hline 1 & 5 C85S10G & $-0,009$ & $-0,024$ & $-0,033$ & $-0,035$ \\
\hline 2 & 5 C85S10H & $-0,027$ & $-0,047$ & $-0,059$ & $-0,063$ \\
\hline 3 & 5 C85S20A & $-0,067$ & $-0,090$ & $-0,098$ & $-0,102$ \\
\hline Yêu cầu của tiêu chuẩn TCVN 9501:2015 & - & - & - & Max 0,15 (giá trị tuyệt đối) \\
\hline
\end{tabular}

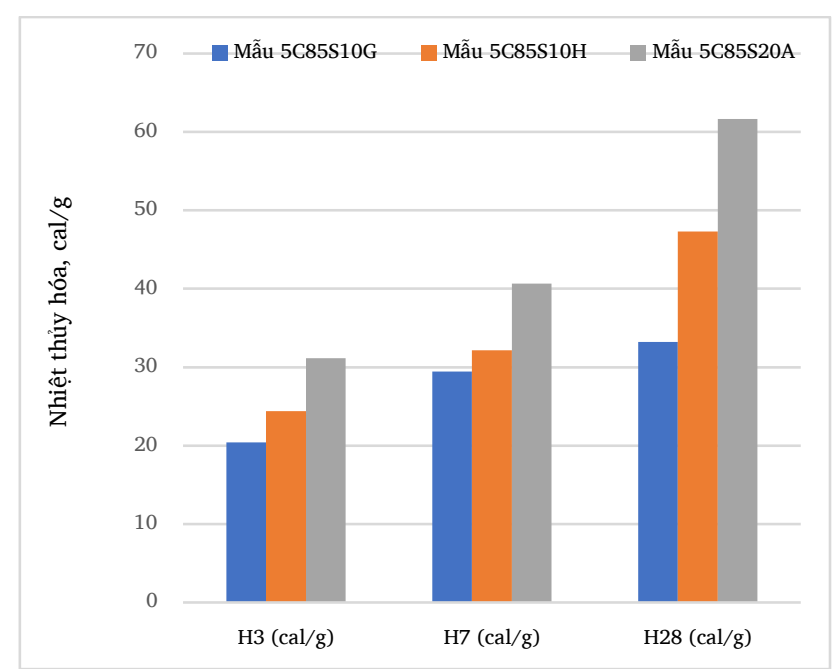

Hình 111. Nhiệt thủy hóa của xi măng.

\section{Nhận xét:}

- Cả 3 mẫu xi măng đều có nhiệt thủy hóa thỏa mãn yêu cầu của tiêu chuẩn BS EN 15753:2010+A1:2015, độ co khô sau 28 ngày thỏa mãn TCVN 9501:2013. Trong đó, nhiệt thủy hóa và độ co khô của các mẫu sử dụng FGD nguyên khai thấp nhất, tiếp sau là mẫu sử dụng FGD dạng nửa nước và mẫu sử dụng FGD khan có nhiệt thủy hóa và độ co khô cao nhất trong các mẫu thử nghiệm.

- Đối với mẫu cấp phối sử dụng thạch cao FGD nguyên khai và FGD dạng nửa nước đều có nhiệt thủy hóa thỏa mãn loại tỏa nhiệt rất thấp theo TCVN 7712:2013 [9]. Riêng đối với cấp phối sử dụng thạch cao FGD khan thì thỏa mãn loại xi măng tỏa nhiệt thấp theo TCVN 7712:2013.

\section{Kết luận}

Từ các kết quả nghiên cứu cho kết luận sau:

- Hoàn toàn chế tạo được xi măng siêu Sulfate sử dụng các nguồn nguyên vật liệu phế thải tại Việt Nam gồm xỉ lò cao và thạch cao FGD - phụ phẩm của các nhà máy đốt than phun đáp ứng loại $32,5 \mathrm{~N}$ và 42,5N theo tiêu chuẩn BS EN 15753:2010 + A1:2015.

- Thạch cao FGD với dạng hemihydrat và anhydrit có tác dụng tốt với sự phát triển cường độ của đá xi măng. Đồng thời, các mẫu cũng bền trong các môi trường xâm thực Sulfate và nước biển.

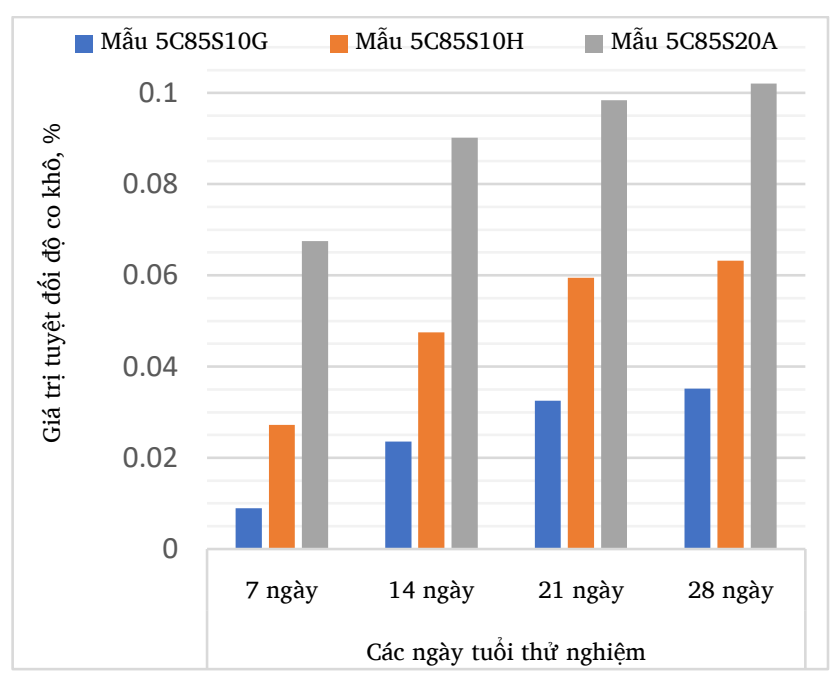

Hình 122. Độ co khô của xi măng.

- Đá xi măng có sản phẩm thủy hóa chủ yếu là khoáng ettringite, thạch cao dư và C-S-H. Mẫu xi măng có cường độ ở tuổi sớm do sự hình thành khoáng ettringte.

- Xi măng có nhiệt thủy hóa thuộc nhóm tỏa nhiệt thấp và rất thấp, độ co khô thỏa mãn yêu cầu kỹ thuật của tiêu chuẩn xi măng đa cấu tử.

\section{Tài liệu tham khảo}

[1]. BS EN 15743:2010+A1:2015: SuperSulfated cement. Composition, specifications and conformity criteria

[2]. TCVN 6017:2015 Xi măng - Phương pháp xác định thời gian đông kết và độ ổn định thể tích

[3]. TCVN 6016:2011 Xi măng - Phương pháp thử - Xác định cường độ

[4]. TCVN 9501:2013: Xi măng đa cấu tử

[5]. TCVN 8824:2013 Xi măng - Phương pháp xác định độ co khô của vữa

[6]. TCVN 6070:2007 Xi măng - Phương pháp xác định nhiệt thủy hóa

[7]. Qingyong Wu, Qingzong Xue, Zhuqing Yu, Research status of super Sulfatee cement, Journal of Cleaner Production 294 (2021) 126228

[8]. Z. Grounds, D.V. Nowell, F.W. Wilburn, The influence of temperature and different storage conditions on the stability of supersulphated cement, J. Therm. Anal. 41(1994) 687-699

[9]. TCVN 7712:2013 Xi măng pooc lăng hỗn hợp ít tỏa nhi 